\title{
SLURRY PHASE IRON CATALYSTS FOR INDIRECT COAL LIQUEFACTION
}

Contract No. DE-FG22-95PC95210

to

The University of New Mexico

$$
\text { 7/5/95-7/4/98 }
$$

First Semi-Annual Progress Report

Covering the Period from 7/5/95 - 1/4/96

\section{Prepared for}

U. S. Department of Energy

Pittsburgh Energy Technology Center

PETC Project Manager: Richard E. Tischer

\section{Submitted by}

Abhaya K. Datye, Professor

Chemical \& Nuclear Engineering and

Director, Center for Microengineered Ceramics

University of New Mexico

Albuquerque, NM 87131

February 8, 1996

\section{MASTER}




\section{DISCLAIMER}

Portions of this document may be illegible in electronic image products. Images are produced from the best available original document. 


\section{Objectives}

The objectives of this project are to study factors that control the attrition resistance of slurry phase Fe catalysts, and to synthesize novel precipitated catalysts that overcome some of the limitations of current generation catalysts. A secondary objective is to study catalyst-binder interactions using model catalysts.

\section{Executive Summary}

This report covers the first six months of this three year grant under the University Coal Research program. During this period we have continued our work on understanding the attrition of precipitated iron catalysts and how it is related to the activation process. We have commenced a study of $\mathrm{Fe} /$ silica interactions to provide a fundamental understanding of the how silica binders influence the activity and attrition resistance of these catalysts. The influence of $\mathrm{Cu}$ on the reduciblity of $\mathrm{Fe}$ catalysts was also studied and shows clearly that small amounts of $\mathrm{Cu}$ can play a significant role in facilitating reduction of $\mathrm{Fe}_{2} \mathrm{O}_{3}$ to $\alpha-\mathrm{Fe}$. This work was submitted to the 11th International Congress on Catalysis and has been accepted for oral presentation and publication in the proceedings. We have worked with Nancy Jackson at Sandia National Laboratories to investigate the nature of carbon deposits in Fe F-T catalysts, and we find a very good correlation between the peak temperature in TPR and the nature of the carbon as seen by TEM. We have analyzed a set of samples we received from Dr. Burtron Davis, University of Kentucky by XRD and TEM to investigate causes of catalyst deactivation. Both XRD and TEM seem to show that the active catalyst contains small crystallites of iron carbide while the deactivated catalyst shows significant transformation into large crystals of magentite. We are convinced that improper passivation of these catalysts can contribute to mis-identification of the phases in working F-T catalysts. To this end, we have submitted a manuscript to Catalysis Letters on the role of proper passivation techniques which has been accepted for publication.

\section{Attrition of precipitated Fe catalysts}

To provide a comprehensive summary of this aspect of our work, which was initiated by funding from Sandia National Laboratories, we have enclosed a reprint of a paper just published in Applied Catalysis and one that was presented at the International Gas Conversion Conference in November 1995. Both these papers show that the attrition of these catalysts occurs on two length scales. First, the weak binding between the primary particles of $\mathrm{Fe}_{2} \mathrm{O}_{3}$ can cause break-up of the catalyst. Second, activation of the catalyst causes a nano-scale attrition due to the transformation of $\mathrm{Fe}_{2} \mathrm{O}_{3} \rightarrow-\mathrm{Fe}_{3} \mathrm{O}_{4} \rightarrow \chi-\mathrm{Fe}_{5} \mathrm{C}_{2}$ resulting in the transformation of the parent crystals of $\mathrm{Fe}_{2} \mathrm{O}_{3}$ into crystallites of the iron carbide. 


\section{Implications for the Design of Attrition Resistant Catalysts}

The first step for the design of attrition resistant catalysts is to make the aggregates of $\mathrm{Fe}_{2} \mathrm{O}_{3}$ (as-prepared) stronger than they are in the precipitated and spray dried catalyst (L-3950). Since kaolin is a binder that has been used for this purpose, we first examined the binder containing catalyst (L-3950) by sedigraph size distribution analysis as it was subjected to ultrasound to cause catalyst break-up. The catalyst with binder was found to be as weak as the binderless catalyst. The cause for this becomes apparent when we look at the plate-like morphology of the binder and the large particle size relative to the primary particles of $\mathrm{Fe}_{2} \mathrm{O}_{3}$. Since silica is a binder commonly used for these catalysts, we have initiated a fundamental understanding of Fe/silica interactions to understand why silica lowers the activity of the Fe catalyst (affecting the reducibility of the Fe phase, forming mixed oxides etc.). Preliminary results show that when Fe and silica were co-precipitated (starting from ferric nitrate and TEOS) we formed an amorphous glassy phase that could not be reduced at all. However, when the iron was precipitated onto a silica surface, we were able to reduce the iron and form a carbide phase. This catalyst did exhibit activity for F-T synthesis, although lower than the unsupported precipitated catalyst. Finally, we also explored the role of $\mathrm{Cu}$ on the reducibility of the $\mathrm{Fe}_{2} \mathrm{O}_{3}$ and we found that $\mathrm{Cu}$ accelerated the reduction to $\alpha-\mathrm{Fe}$. Even $1 \mathrm{wt} \% \mathrm{Cu}$ caused a significant acceleration of the reduction process with the effect being less pronounced as $\mathrm{Cu}$ loading was increased. This part of our work is summarized in a paper we submitted last fall for the International Congress on Catalysis to be held at Baltimore in June 1996. This paper has been accepted for oral presentation, subject to minor corrections and will be published in the proceedings. A copy of the submitted version of this paper is attached to this report, and should be treated as a draft since some further corrections will be made to address the reviewers' comments.

\section{The importance of Passivation in the study of F-T catalysts}

In our previous work, we became aware of the possible artifacts caused by improper passivation and hence submitted a note to Catalysis Letters demonstrating this aspect. Essentially, if $\mathrm{Fe}_{2} \mathrm{O}_{3}$ is converted to carbide by pretreatment in $\mathrm{CO}$ at $523 \mathrm{~K}$ and then exposed to air without proper passivation, instead of the carbide phase we will see $\mathrm{Fe}_{3} \mathrm{O}_{4}$ on the surface. The effects will be much more pronounced if we are studying the reduction of $\mathrm{Fe}_{2} \mathrm{O}_{3}$ to the $\alpha$-Fe phase which, infact, is pyrohoric when exposed to air. To properly passivate these samples, we switched from the reactant gas to flowing Helium at reaction temperature, cooled to room temperature and then introduced small amounts of $\mathrm{O}_{2}$ (up to $1 \%$ ) in flowing He. Following this proceedure, we found that the film of $\mathrm{Fe}_{3} \mathrm{O}_{4}$ formed on the surface of $\alpha$-Fe after proper passivation is no more than a few nm thick. On a carbide sample, proper passivation may cause no growth of $\mathrm{Fe}_{3} \mathrm{O}_{4}$ at all if there is sufficient carbon on the surface as a result of the preparation procedure (see below). The accepted manuscript to Catalysis Letters is attached to this report. 


\section{The nature of carbon deposits in F-T catalysts}

In previous work, we had found that when we removed a catalyst from a reactor after F-T synthesis (at atmospheric pressure, fixed bed reactor, $523 \mathrm{~K}, \mathrm{H}_{2} / \mathrm{CO}=0.7$ ) we found amorphous carbonaceous deposits that formed characteristic haloes around the iron carbide crystallites. On the other hand, the $\mathrm{Fe}_{3} \mathrm{O}_{4}$ phase in the catalyst showed no such amorphous layers. Figure 1 on the next page shows a low magnification view of this catalyst after being in an F-T environment for 40 hours. Figure 2 on the following page shows a higher magnification view of this catalyst where it is clear that the magnetite phase is free of any surface layers while the iron carbide is covered with a well-defined amorphous layer. In our work, we have observed that heating to elevated temperatures can transform this surface layer into a graphitic phase. In collaboration with Nancy Jackson at Sandia National Laboratories, we have performed a careful study of the nature of these carbon deposits. We find that the amorphous layer seen in Figs 1 and 2 can be very readily hydrogenated to methane in flowing $\mathrm{H}_{2}$. It takes higher temperatures to convert graphite into methane. Furthermore, we can clearly see a peak arising from the carbide carbon in the bulk. The removal of these carbon species during TPR can be correlated with TEM images of the catalyst showing the loss of the surface amorphous films, or the transformation of bulk carbide into $\alpha-\mathrm{Fe}$, etc. A detailed manuscript is under preparation and will be submitted shortly for publication. This work provides conclusive evidence that the amorphous carbonaceous films, 'haloes,' seen on the iron carbide constitute the 'active' carbon (probably $\mathrm{CH}_{x}$ ) species. The lack of these species on the magnetite further confirms that magnetite is inactive for the F-T synthesis.

\section{Mechanisms of Catalyst Deactivation}

We received a set of samples from Dr. Burtron Davis at the University of Kentucky that exhibited differing activities for $\mathrm{CO}$ hydrogenation. These catalysts are listed below:

\begin{tabular}{|l|l|l|}
\hline LGX-171 & $\begin{array}{l}\text { Precipitated } 100 \mathrm{Fe} / 4.4 \mathrm{Si} / 1.0 \mathrm{~K} \text { catalyst after } 3164 \\
\text { hours of } \mathrm{FTS}\left(\mathrm{H}_{2} / \mathrm{CO}=0.7\right) \text { at } 270{ }^{\circ} \mathrm{C} \text { and } 175 \text { psig. }\end{array}$ & $\begin{array}{l}\mathrm{CO} \text { conversion at } \\
\text { end of run was } \\
24 \%\end{array}$ \\
\hline LGX-175 & $\begin{array}{l}\text { Precipitated } 100 \mathrm{Fe} / 4.4 \mathrm{Si} / 1.0 \mathrm{~K} \text { catalyst after } 1160 \\
\text { hours of } \mathrm{FTS}\left(\mathrm{H}_{2} / \mathrm{CO}=0.7\right) \text { at } 270{ }^{\circ} \mathrm{C} \text { and } 175 \text { psig. }\end{array}$ & $\begin{array}{l}\mathrm{CO} \text { conversion at } \\
\text { end of run was } \\
79 \%\end{array}$ \\
\hline LGX-195 & $\begin{array}{l}\mathrm{C}-73 \mathrm{H} 2\left(\mathrm{UCI} \mathrm{C}-73 \text { catalyst reduced } \mathrm{in}_{2} \text { and }\right. \\
\text { passivated) after } 192 \text { hours of } \mathrm{FTS}\left(\mathrm{H}_{2} / \mathrm{CO}=0.7\right) \text { at } \\
270{ }^{\circ} \mathrm{C} \text { and } 175 \text { psig. }\end{array}$ & $\begin{array}{l}\mathrm{CO} \text { conversion at } \\
\text { end of run was } \\
32 \%\end{array}$ \\
\hline
\end{tabular}

These catalysts were obtained in wax so as to preserve the microstructure during exposure to ambient atmosphere. We first examined the catalysts by XRD and the results are shown in the Figures 3-5. 
The XRD patterns show a broad background feature at around $2 \theta$ of $19^{\circ}$ and two unidentified peaks at $2 \theta$ values between $20^{\circ}$ and $25^{\circ}$ that come from the hydrocarbon wax. The other phases seen by XRD are magnetite and several peaks due to iron carbide. Our preliminary analysis shows that both samples that exhibit a low conversion of $\mathrm{CO}$ show prominent magnetite peaks. The sample that shows high activity (LGX-175) has magnetite peaks which are considerably lower in intensity. The carbide peaks are broader in the more active catalyst indicating the presence of small crystallites of iron carbide. Fig. 6 shows a TEM image of catalyst LGX-175. This sample was stripped of the wax by heating in flowing Helium to vaporize the wax which was collected downstream. We adopted this procedure because our previous analysis of samples obtained from Dr. Burtron Davis that had been soxhlet extracted showed evidence of surface oxidation. We feel that the high temperature during soxhlet extraction may make it easier to get corrosive oxidation of the active iron surface even with the traces of $\mathrm{O}_{2}$ that may be present. By stripping the wax in helium we do get some carbonization of the wax but we hope to better preserve the microsctructure of the catalyst. As seen in Fig. 6, this catalyst shows small particles of carbide with well defined haloes similar to those seen in our previous work (see Fig. 1 and 2). The surface carbon deposits from the hydrocarbon can be differentiated from the amorphous carbon that is present on the carbide. The TEM observations confirm the XRD findings and show that the active catalyst contains crystallites of iron carbide while the deactivated catalyst shows large particles of magnetite. These results are preliminary observations from catalyst samples obtained from different runs and we hope to soon obtain from Dr. Davis a set of samples from a single run where sample have been collected as a function of time. The analysis of these samples should provide further clues to understanding catalyst deactivation.

\section{Future Work}

We will continue our work on catalyst attrition resistance. In particular, we will refine our sedigraph approach to attrition resistance measurement by studying the strength of agglomerates of commonly available catalyst supports. This should provide us a reference scale to compare the strength of the precipitated iron catalysts. The work on catalyst binder interactions will also be continued to provide a thorough understanding of how Fe and silica interact. For this purpose F-T activity tests in our atmospheric pressure packed bed reactor will be used to provide an indication of the activity of the catalysts we prepare.

\section{DISCLAIMER}

\footnotetext{
This report was prepared as an account of work sponsored by an agency of the United States Government. Neither the United States Government nor any agency thereof, nor any of their employees, makes any warranty, express or implied, or assumes any legal liability or responsibility for the accuracy, completeness, or usefulness of any information, apparatus, product, or process disclosed, or represents that its use would not infringe privately owned rights. Reference herein to any specific commercial product, process, or service by trade name, trademark, manufacturer, or otherwise does not necessarily constitute or imply its endorsement, recommendation, or favoring by the United States Government or any agency thereof. The views and opinions of authors expressed herein do not necessarily state or reflect those of the United States Government or any agency thereof.
} 


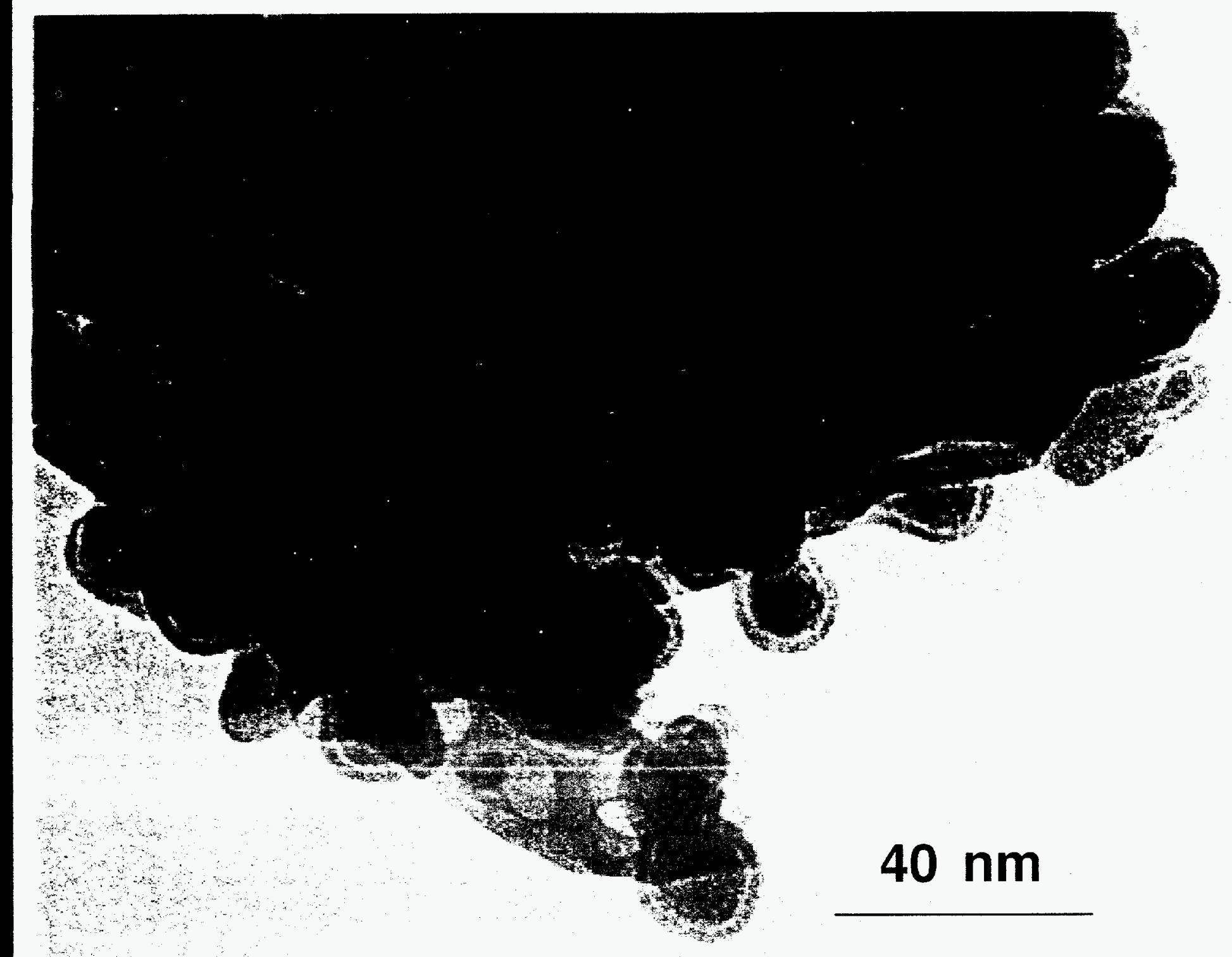

Fig. 1 Transmission Electron Micrograph of UCI catalyst 1185-70-370 after 45 hours of reaction at $523 \mathrm{~K}$ with $\mathrm{H}_{2} / \mathrm{CO}$ ratio $=0.7$. The parent crystals of $\mathrm{Fe}_{2} \mathrm{O}_{3}$ have broken up into crystallites of iron carbide. In this micrograph all of the carbide crystallites are covered with amorphous carbonaceous layers while the unreduced magnetite is devoid of any surface films. 


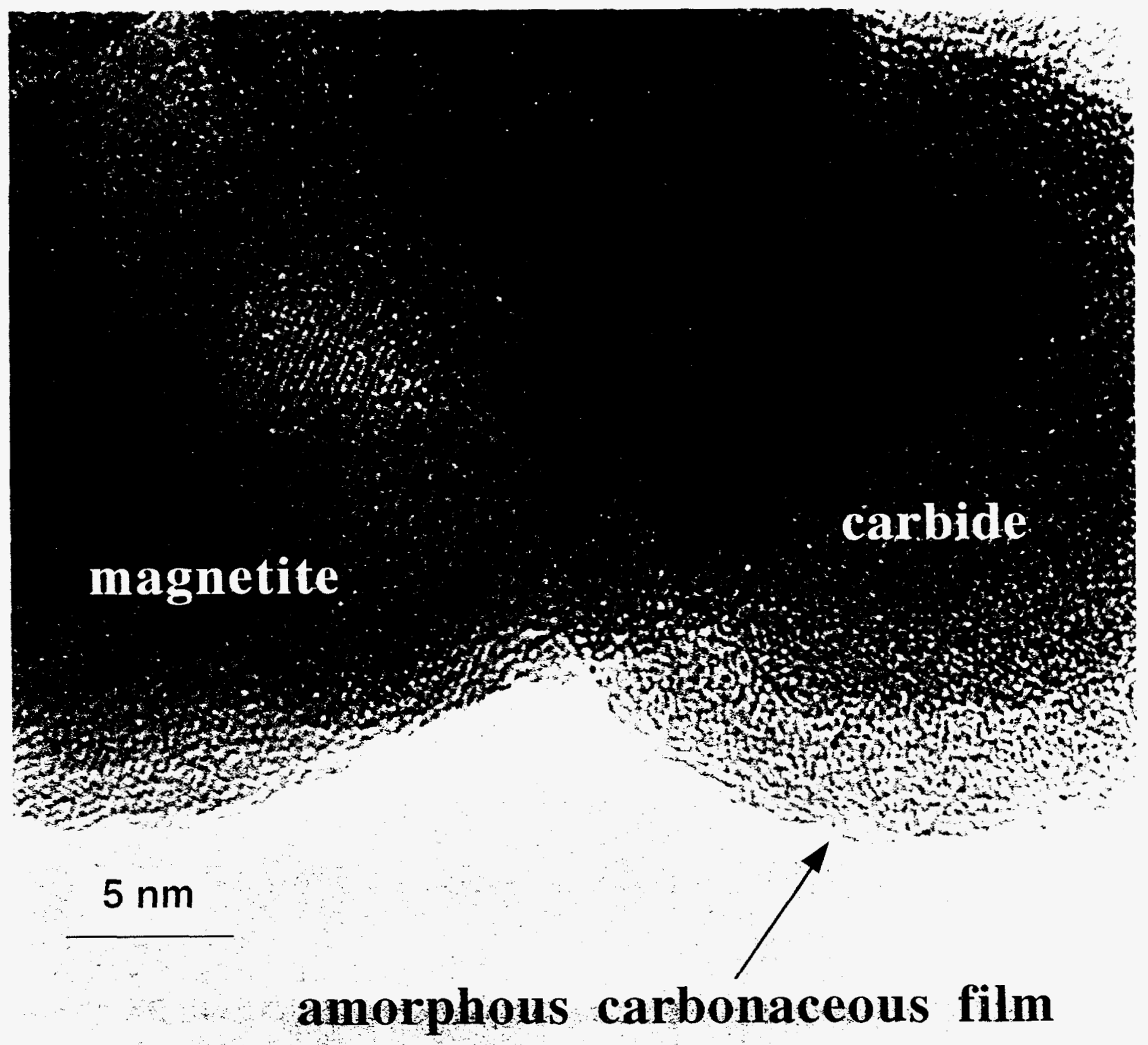

Fig. 2 Higher magnification view of the region in Fig. 1 showing the magnetite phase (free of any surface carbon film) and the carbide with an amorphous carbonaceous layer. This layer is very easily hydrogenated to methane suggesting that it represents the pool of 'active' carbon on the catalyst surface. 


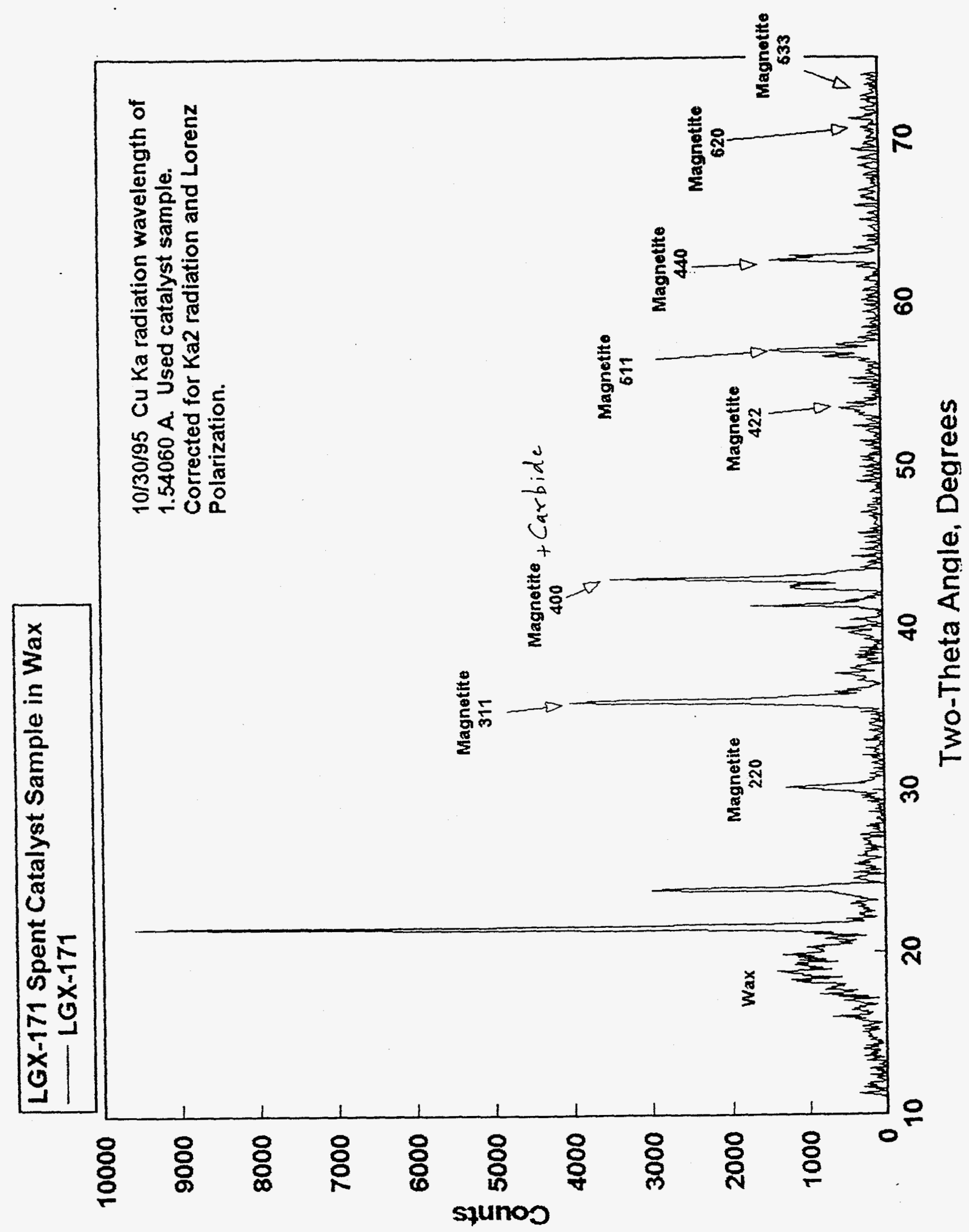

Fig. 3 XRD pattern of catalyst LGX-171 obtained from Dr. Burtron Davis. The magnetite peaks are very prominent. 


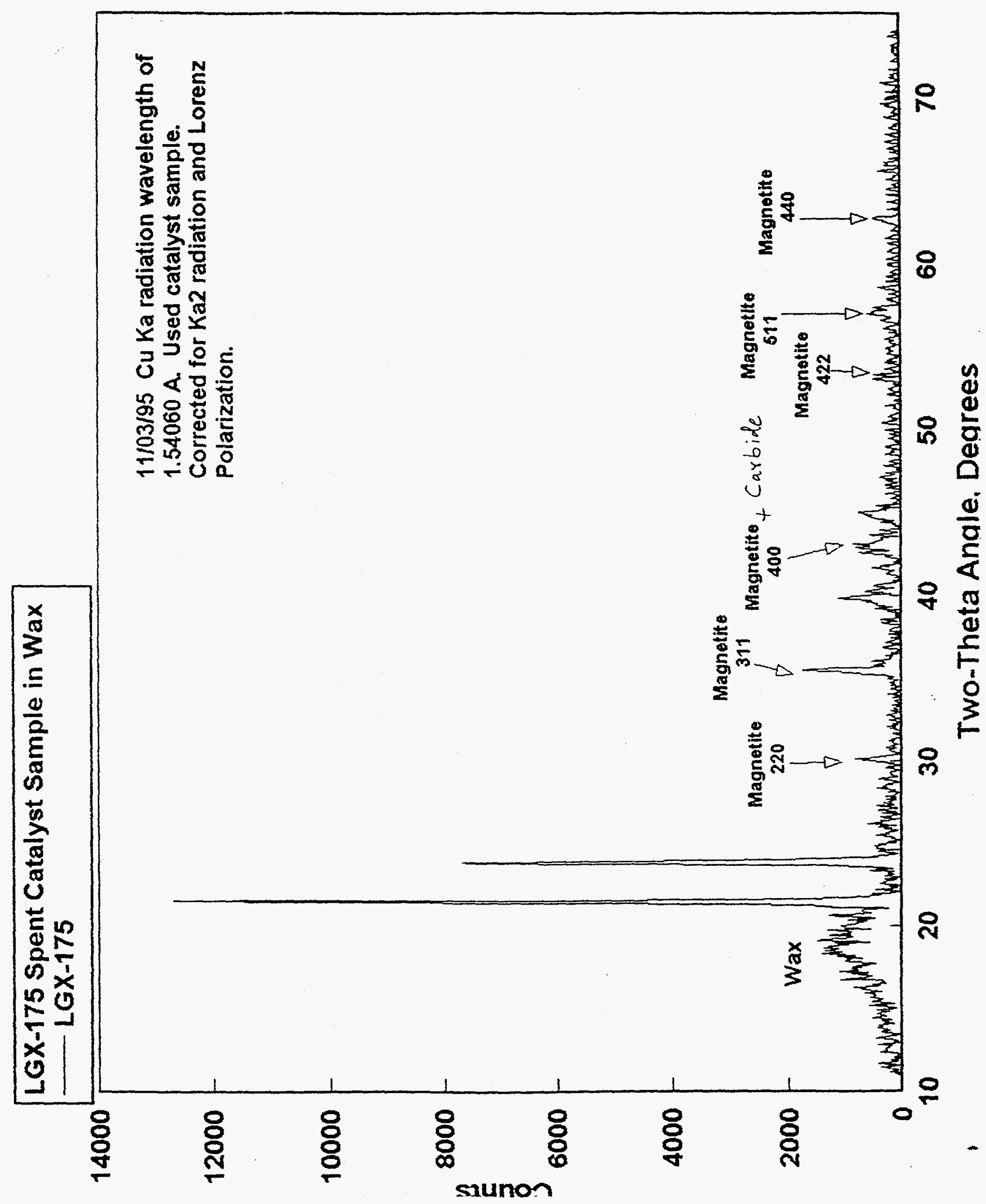

Fig. 4 XRD pattern of catalyst LGX -175 obtained from Dr. Burtron Davis. The magnetite peaks are less pronounced than in Fig, 3 or Fig. 5 . Several carbide peaks are seen and they are broad indicating they come from smaller 


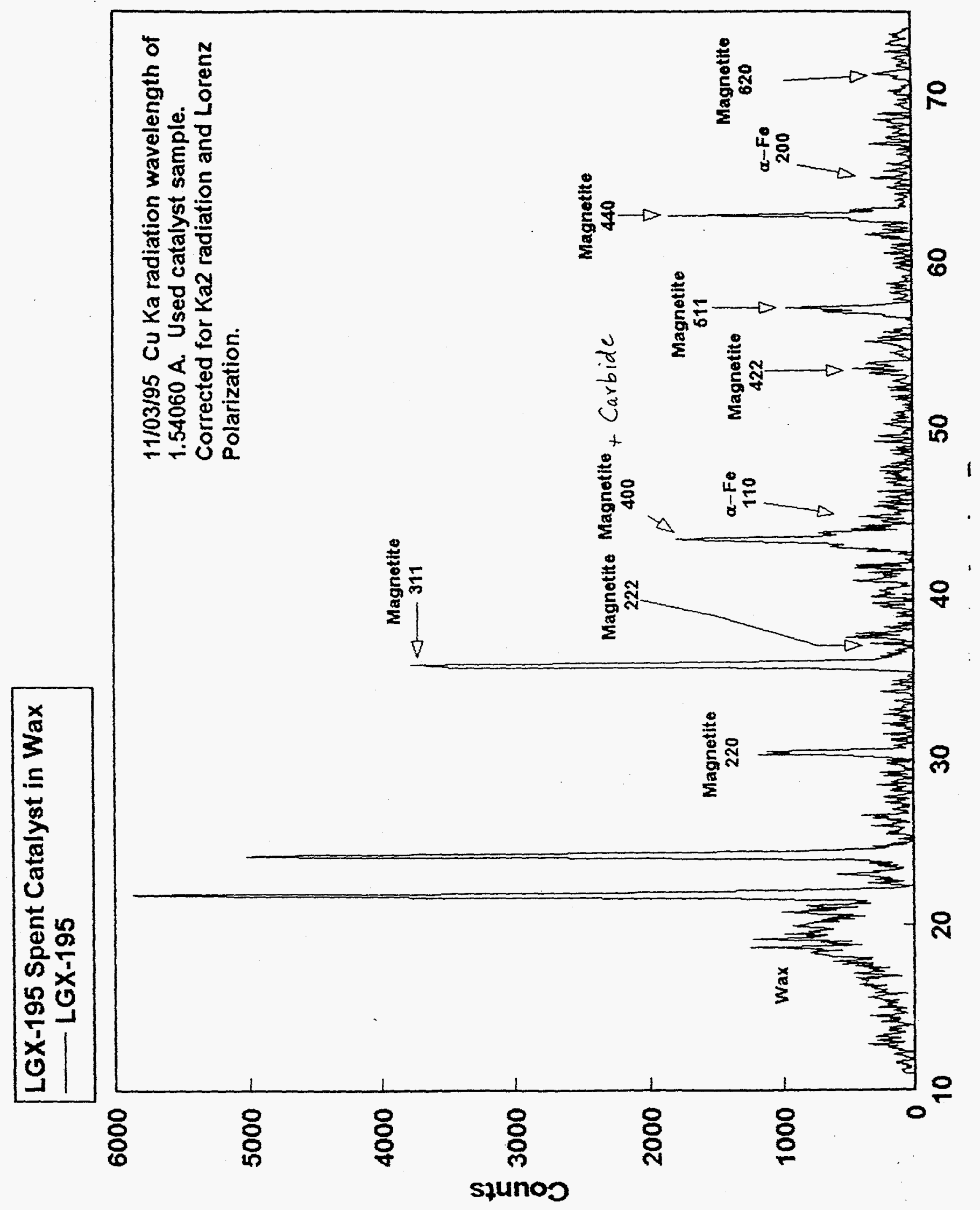

Fig. 5 XRD pattern of catalyst LGX -195 obtained from Dr. Burtron Davis. The prominent magnetite peaks are consistent with the low CO hydrogenation 


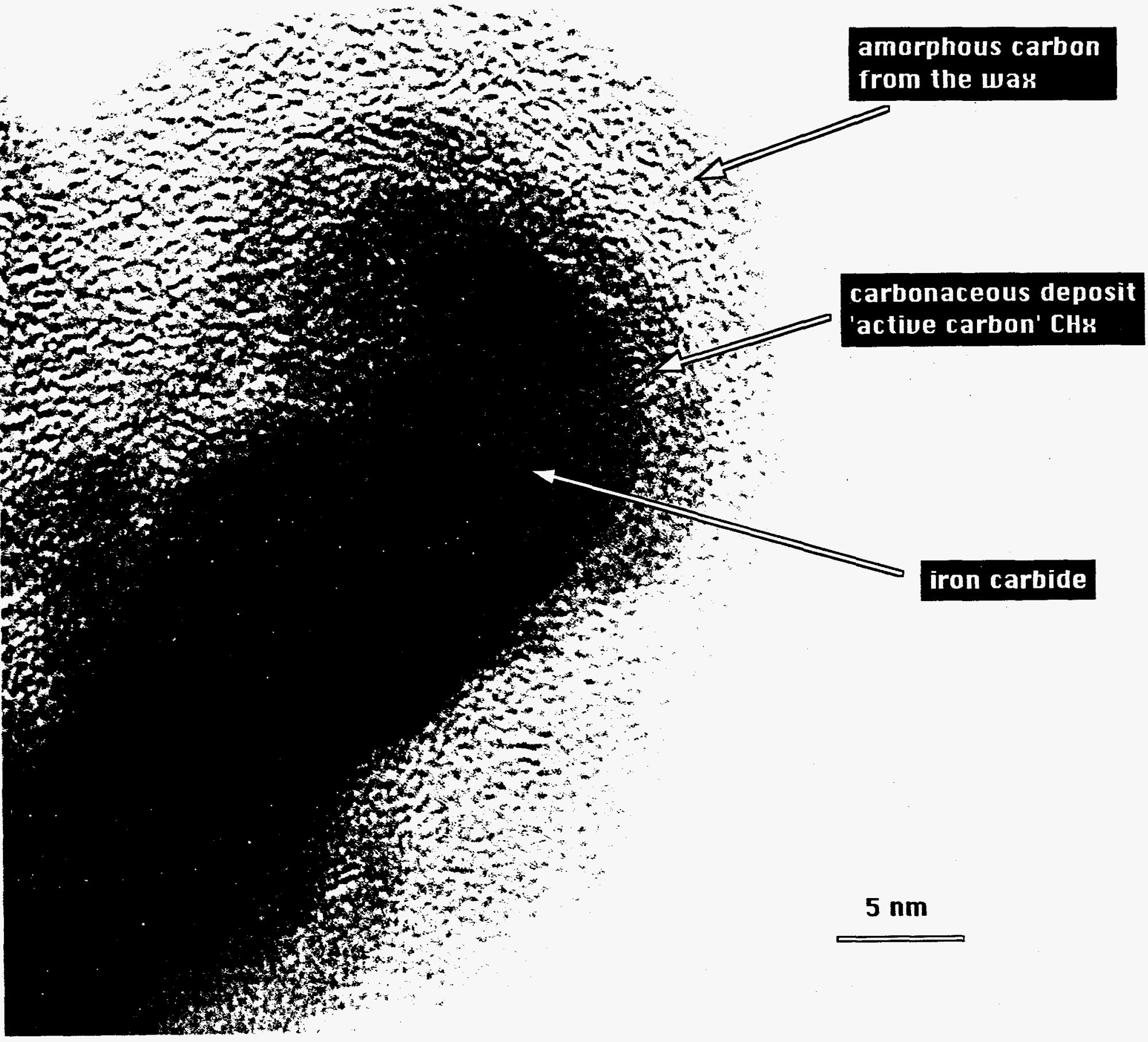

Fig. 6 High resolution TEM image of catalyst LGX-175 after stripping the wax by heating in flowing helium. Carbide crystallites are seen covered by an amorphous carbonaceous layer (similar to that seen in Fig. 1 and 2). The surface amorphous layer arises from the carbonization of the wax and can be distinguished from the underlying catalyst. 